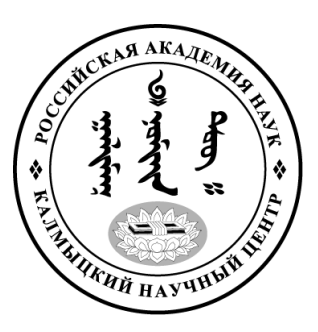

Published in the Russian Federation

Oriental Studies (Previous Name: Bulletin of the Kalmyk Institute for

Humanities of the Russian Academy of Sciences)

Has been issued as a journal since 2008

ISSN: 2619-0990; E-ISSN: 2619-1008

Is. 4, pp. 682-690, 2019

DOI: $10.22162 / 2619-0990-2019-44-4-682-690$

Journal homepage: https://kigiran.elpub.ru

УДК $811.512 .3+811.512 .31$

\title{
Квазисинонимические уступительные конструкции в бурятском языке
}

\author{
Надежда Баировна Даржаева ${ }^{1}$ \\ ${ }^{1}$ Институт монголоведения, буддологии и тибетологии СО РАН (д. 6, ул. Сахьяновой, 670047 \\ Улан-Удэ, Российская Федерация) \\ старший научный сотрудник \\ ORCID: 0000-0002-1701-2329. E-mail: dnadezhda@mail.ru
}

\begin{abstract}
Аннотация. Введение. Синтаксис сложного предложения в языках алтайской языковой общности характеризуется наличием большого количества синонимических конструкций, которые на определенном этапе их изучения следует дифференцировать с целью, во-первых, выявления системообразующих оппозиций, во-вторых, определения вектора развития конкретной конструкции. Гипотеза исследования состоит в признании таких конструкций квазисинонимическими, т. е. не полными синонимами, различающимися теми или иными оттенками значения или стиля. В статье впервые в монголоведении предпринимается попытка дифференциации квазисинонимических полипредикативных конструкций со значением уступки. В современном бурятском языке уступительно-противительные отношения выражаются четырьмя разноструктурными конструкциями: с деепричастием на -бАшье, с частицами haa и -шье, с уступительно-противительной скрепой аaд, бифинитной конструкцией со скрепами на базе служебного глагола говорения гэ-. Материаль и методы. Материалом исследования послужили примеры из бурятских художественных произведений, размещенных в Электронном корпусе бурятского языка. Использование методов контекстного анализа, интроспекции и лингвистического эксперимента позволило вскрыть ранее не описанные дифференциальные признаки. Результаты. Нам удалось выявить разного рода семантические оттенки: принципиальная моносубъектность, расширенный временной интервал между событиями, осложнение модусным компонентом. Таким образом, дифференциация квазисинонимических конструкций способствует уточнению и нормированию отношений между ними.
\end{abstract}

Ключевые слова: уступительные конструкции, стилистическая и семантическая дифференциация, квазисинонимические полипредикативные конструкции, синтаксис монгольских языков

Благодарность. Работа выполнена в рамках государственного задания (проект XII.193.1.5. Ментальность монгольских народов в зеркале языка, номер госрегистрации № АААА-А17-117021310266-8).

Для цитирования: Даржаева Н. Б. Квазисинонимические уступительные конструкции в бурятском языке. Oriental Studies. 2019;(4):682-690. DOI: 10.22162/2619-0990-2019-44-4-682-690. 
UDC $811.512 .3+811.512 .31$

\title{
Quasi-Synonymous Concessive Constructions in the Buryat Language
}

\author{
Nadezhda B. Darzhaeval \\ ${ }^{1}$ Institute for Mongolian, Buddhist and Tibetan Studies, Siberian Branch of the RAS (6, Sakhyanova \\ St., Ulan-Ude 677047, Russian Federation) \\ Cand. Sc. (Philology), Senior Research Associate \\ ORCID: 0000-0002-1701-2329. E-mail: dnadezhda@mail.ru
}

\begin{abstract}
Introduction. The syntax of the complex sentence in Altaic languages is characterized by a large number of synonymous constructions. Goals. The paper seeks to differentiate the synonymous constructions, firstly, to systemically identify important oppositions and, secondly, to determine development vectors of certain constructions. The study hypothesizes such constructions as actually quasi-synonymous, i.e. those are not complete synonyms and differ in shades of meaning or style. For the first time in Mongolian studies, the paper attempts to differentiate quasi-synonymous polypredicative constructions with concessive meanings. In modern Buryat, concessive-adversative relations are expressed by four structurally different constructions, namely: ones containing adverbial participles ending with -bashye (-бAшьe), ones with the particles $\gamma a a$ and -shye (haa, -ube), ones with the concessive-adversative particle $a a d$ ( $a a d)$, and ones containing the bifinite construction with particles on the basis of the service verb of saying - ge (2э-). The study investigates examples from Buryat imaginative literature placed in the online Buryat corpus. Methods and results. The use of methods of contextual analysis, introspection and linguistic experiment makes it possible to identify various semantic shades, such as principal mono-subjectivity, an extended time interval between events, and a complication with the modus component. Thus, the differentiation of quasi-synonymous constructions contributes to the refinement and rationing of relations between them.

Keywords: concessive constructions, stylistic and semantic differentiation, quasi-synonymous polypredicative constructions, syntax of Mongolic languages

Acknowledgements: The research was conducted within the state assignment of FASO of Russia (project XII.193.1.5. 'Mentality of Mongolic Peoples in the Mirror of Language'. State Reg. No. AAAA-A17-117021310266-8).

For citation: Darzhaeva N. B. Quasi-Synonymous Concessive Constructions in the Buryat Language. Oriental Studies. 2019;(4): 682-690. DOI: 10.22162/2619-0990-2019-44-4-682-690.
\end{abstract}



Введение. В современном языкознании есть немало работ, посвященных уступительному смыслу. В. Ю. Апресян в своей статье «Уступительность как системообразующий смысл» [Апресян 2006: 87] выделяет два важнейших подхода в исследовании этого смысла: семантический (реализован в работах: [König 1991; Ляпон 1986; Теремова 1986; Храковский 1998; Урысон 2002]) и риторический (реализован в работах [Wierzbicka 1987; Арутюнова 1988; Паршин 1988; Булыгина, Шмелев 1997]). Первые анализируют прежде всего семантику отдельных уступительных единиц, вторые их роль в построении диалога и полемики.

Уступительными называются сложные отношения, сочетающие компоненты причинного, условного и противительного значений (несоответствие ожиданиям) и отображающие неестественное, конфликтное сосуществование или следование ситуаций [Типология уступительных ... 2004: 10] 'хотя.., но'. Подобное определение находим и у Л. Г. Валиевой: «Уступительные отношения строятся на противопоставлении двух ситуаций, формируются на базе условных, причинно-следственных, противительных значений» [Валиева 2014: 103].

Уступительные предложения традиционно включаются в группу предложений
\end{abstract}


обусловленности, но при этом они противопоставляются причинно-следственным, целевым и условным, основанным на идее порождения ситуации-2 ситуацией-1. Некоторые исследователи не согласны с тем, что уступительные отношения входят в круг значений обусловленности, считая, что «уступительное значение на эту идею не опирается, а скорее отталкивается от нее, поскольку ситуация-2 возникает в этом случае вопреки существованию ситуации- 1 , которая является не порождающей ситуацию-2, а так или иначе препятствующей ее реализации. По существу, уступительные отношения есть отношения ,антиобусловленности“» [Шувалова 1990: 55].

В ситуации уступки естественно ожидаемое следствие опускается, и по какой-то превосходящей причине происходит иное событие-следствие. Другими словами, обязательным компонентом уступительности признается смысл «вопреки ожидаемому» [Русская грамматика 1980: 586; Ляпон 1986: 137]. В пресуппозиции говорящего существует некая ожидаемая связь (априорная истина по определению М. В. Ляпон [Ляпон 1986: 137]), которая не находит выражения в высказывании, а постулируется совершенно противоположная истина - актуальная.

Как пишут авторы монографии «Типология уступительных конструкций», «концепт 'уступительное значение' является родовым и реализуется в виде концептов 'причинно-уступительное значение' и 'условно-уступительное значение', причем последний концепт представлен двумя разновидностями: 'реальное (выполнимое) условно-уступительное значение' и 'ирреальное (невыполнимое) условно-уступительное значение'» [Типология уступительных...2004: 14].

Отметим еще, что в русской грамматике отдельно рассматриваются уступительные конструкции (подчинительные) и противительные (сочинительные). Для бурятского языка противопоставление сочинения и подчинения структурно нерелевантно; серьезных семантических оснований за этим противопоставлением нет, только прагматические (большее логическое ударение на первой части - уступка - или на второй части, противительность). Поэтому мы рассматриваем такие конструкции вместе. Материалом для исследования послужили при- меры из бурятских художественных произведений, размещенных в Электронном корпусе бурятского языка (ЭКБЯ).

\section{Основная часть}

В современном бурятском языке уступительно-противительные отношения выражаются следующими конструкциями:

1. С уступительным деепричастием на -бАшье:

(МСФ) [...V-бАшье (ГПЕ)] 'хотя'

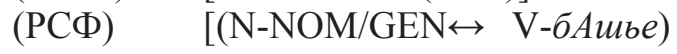
(ГПЕ)] 'хотя'.

2. С условной частицей haa и уступительной частицей -щье:

$[(\mathrm{N}-\mathrm{GEN} \leftrightarrow) \quad$ V-PC-mbe-(NEG) ha$a$-POSS) (ГПЕ)] 'хотя (не)'.

3. С уступительно-противительной скрепой $а a d$ :

[(N-NOM↔) V-PC-(NEG) aad) (ГПЕ)] 'хотя (сначала), но (потом)'.

4. Бифинитной конструкцией со скрепами на базе служебного глагола говорения гэ- в уступительных формах, чаще всего - c показателем уступительного деепричастия:

(ПЕ) гэбэшье гэһэн аад гээщье haа (ПЕ).

Отметим, что все уступительные конструкции однозначно специализированы в первую очередь за счет присутствия уступительной частицы -шье.

Bce четыре конструкции являются устойчивыми квазисинонимическими единицами. Две первые конструкции в современном бурятском языке являются чрезвычайно частотными и конкурентными между собой (около 800 примеров в ЭКБЯ на каждую). Однако Н. Н. Поппе в 1938 г. в своей «Грамматике бурят-монгольского языка» писал о принадлежности уступительной формы на -бАшье баргузинскому, цонгольскому, сартульскому, боханскому и эхиритскому говорам, а формы -шье $h a a-$ литературному языку, агинскому и западным говорам [Поппе 1938: 226].

Скрепа аад рассматривается в числе причинных (причина с несоответствием ожиданиям); но причинное значение у нее вторично, а противительное - первично, поэтому ее нельзя считать неспециализированной. Это естественное следствие того, что уступительное значение является исторически поздним, сложным и комбинированным. 
Итак, конструкция с деепричастием на -бАшье обычно передает действие, произошедшее и завершившееся незадолго до наступления главного, но еще актуальное на момент его наступления. Отличительными чертами этой конструкции являются книжное употребление и выражение подлежащим только 3-го лица:

$\begin{array}{llllc}\text { Дунд-аа } & \text { тэдэ-нэй } & \text { хэлсэ-һэн } & \text { Үг-ье } & \text { хоёр } \\ \text { середина-refl } & \text { они-gen } & \text { говорить-pc.pst } & \text { слово-асс } & \text { два } \\ \text { шэх-ээр-ээ } & \text { дуула-башье, } & \text { Нина } & \text { этигэ-бэ-гүй. } \\ \text { ухо-ins-refl } & \text { слышать-cvb } & \text { Нина } & \text { верить-pst-neg [3sg/pl] }\end{array}$

'Хоть и услышала своими ушами слово, сказанное ими между собой, Нина не поверила’2 [ЭКБЯ. Ч. Цыдендамбаев. ТҮрэл нютагһаa холо. 1958].

С формами длительности в зависимой части события ЗПЕ и ГПЕ происходят одновременно:

\begin{tabular}{|c|c|c|c|c|}
\hline Kaтер & онгосо & холошог & & тамар-жа \\
\hline катер & лодка & далеко & & плавать-cvb \\
\hline тэрэ-нэй & мотоор-ьынь & yhaн & дээг YYр & холуур \\
\hline OH-gen & мотор-poss 3 & вода & pstp & далеко \\
\hline $\begin{array}{l}\text { сууряата-ха } \\
\text { раздаваться-рc.fi }\end{array}$ & $\begin{array}{l}\text { юм. } \\
\mathrm{pcl}\end{array}$ & & & \\
\hline
\end{tabular}

'Хотя катер плывет далеко от берега, звук его мотора далеко раздается над водой' [ЭКБЯ. Ц.-Ж. Жимбиев. Урасхал. 1973].

В конструкции с причастиями в сопровождении сочетания -шье haa самой частотной является форма -AA-шье haa (напомним, что Д. Д. Амоголонов и Т. А. Бертагаев уже предлагали считать ее уступительным деепричастием [Амоголонов 1958: 213; Бертагаев 1968: 27]. Ранее диалектная разговорная форма переходит в литературный язык в связи с выбором хоринского диалекта в качестве его основы. У этой конструкции самая широкая сфера употребления: она встречается со всеми тремя типами значений (причинно-уступительное, условно-уступительное реальное и ирреальное). Это не случайно - морфологически она производна от условной конструкции за счет введения уступительной частицы -шье. Условия появления этих трех вариантов значения близки тем, что были описаны для тюркских языков [Типология уступительных... 2004: 425-452]: здесь важна форма сказуемого главной части. Так, формы не-будущего времени (прошедшего, настоящего, настоящего расширенного) однозначно задают причинно-уступительное значение:

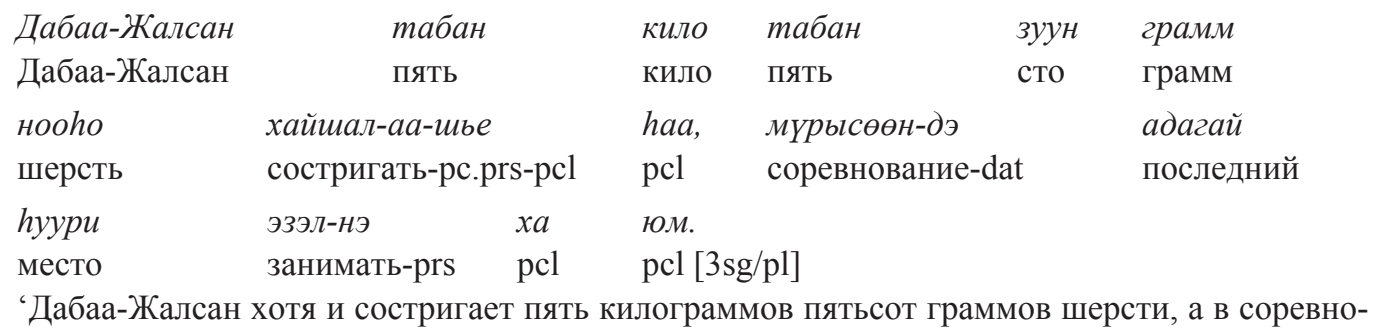
вании занимает последнее место’ [ЭКБЯ. Б. Мунгонов. Баян зүрхэн. 1979].

Кроме того, в отличие от деепричастной конструкции, подлежащее здесь может выражать 1 и 2-е лицо.

Однако намного чаще встречаются при-

\footnotetext{
1 Здесь и далее перевод мой. - Д. H.
}

меры с отрицанием в зависимой предикативной единице (ЗПЕ) - в них, как нам представляется, выражается более жесткая связь между событиями, близкая к 'несмотря на': 
Oriental Studies. 2019. Is. 4

(4)

\begin{tabular}{|c|c|c|c|c|c|}
\hline $\begin{array}{l}\text { тэдэ-нэр } \\
\text { они-pl }\end{array}$ & $\begin{array}{l}\text { ушөө } \\
\text { еще }\end{array}$ & $\begin{array}{l}\text { нэгэ } \\
\text { один }\end{array}$ & $\begin{array}{l}\text { хон-оод } \\
\text { ночевать-сvb }\end{array}$ & $\begin{array}{l}л э, \\
\mathrm{pcl}\end{array}$ & $\begin{array}{l}\text { эсэгэ-mэ-еэ } \\
\text { отец-соm-refl }\end{array}$ \\
\hline иулз-аa-гy & brs-nes & & $\begin{array}{l}\text { буса- } \\
\text { возвр }\end{array}$ & c.fut & $\begin{array}{l}\text { гэжэ } \\
\text { сотр }\end{array}$ \\
\hline
\end{tabular}

ииидэ-бэ-д

решать-pst-pl

'Они переночевали еще одну ночь и, хотя и не встретились со своим отцом, решили вернуться’ [ЭКБЯ. Ц.-Ж. Жимбиев. Урасхал. 1973] — решение далось нелегко.

(5)

$\begin{array}{llll}\text { Арга } & \text { хээ-гүй-шье } & \text { haа, } & \text { Убшэн-иие-нь } \\ \text { лечение } & \text { делать:pc.prs-neg-pcl } & \text { pcl } & \text { болезнь-acc-poss3 } \\ \text { хүнгэн } & \text { болг-оо-m } & & \\ \text { легкий } & \text { делать-pc.prs-2pl } & & \end{array}$

'Хотя Вы и не лечили, но облегчили ему болезнь' [ЭКБЯ. Ч. Цыдендамбаев. ТҮрэл нюmaгhaа холо. 1958] — даже без лечения облегчил состояние.

Формы будущего времени и императива в главной части задают условно-уступительное реальное прочтение конструкции:

(6)
$\begin{array}{ll}\text { Энэ } & \text { ороолон шүдхэр-эй } \\ \text { Этот } & \text { упырь-gen }\end{array}$
эхэнэр
шэнги pstp
хоолой-гоор
хамхар-аa-иье женщина
голос-ins
кричать-pc.prs-pc
hаa-нь, таанад
бу ер-ээрэй-гтьы!
‘Даже если этот упырь закричит женским голосом, вы не приходите!' [ЭКБЯ. Шадаев А. Алтан үндэгэн. 1967].

Как видим, в отличие от предыдущей группы примеров, здесь в зависимой части задается не единственная «антипричина», а альтернативная пара возможностей

- упырь может закричать, а может и не закричать, но в любом случае приходить нельзя. Еще пример с 1-м лицом подлежащего:

\begin{tabular}{|c|c|c|c|c|c|}
\hline $\begin{array}{l}\text { Бидэ } \\
\text { мы }\end{array}$ & $\begin{array}{l}\text { хурдан } \\
\text { быстрый }\end{array}$ & $\begin{array}{l}\text { морин-ой } \\
\text { конь-gen }\end{array}$ & $\begin{array}{l}\text { хойноһоо } \\
\text { pstp }\end{array}$ & $\begin{array}{l}\text { гүй-гөө-шье } \\
\text { бежать-pc.prs-pcl }\end{array}$ & $\begin{array}{l}\text { haa, } \\
\mathrm{pcl}\end{array}$ \\
\hline $\begin{array}{l}\text { хэзээ-ши } \\
\text { когда-р }\end{array}$ & & 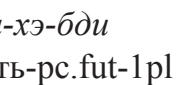 & & & \\
\hline
\end{tabular}

Значение акцентированного утверждения выражается, как и в русском языке, контекстно: «... ситуация, представленная в придаточной части, имеет гиперболиче-

ский характер и часто вообще отвергается. Тем самым усиливается убедительность утверждаемого в главной части» [Русская грамматика 1980: 589]. Пример:

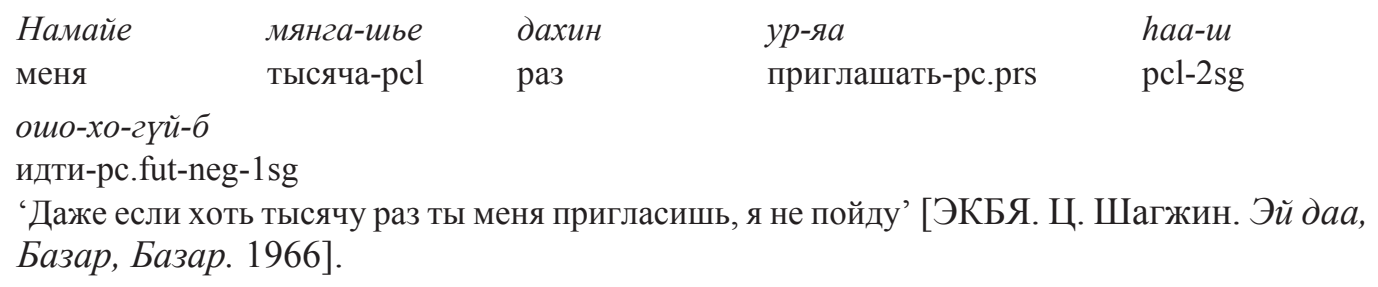


Наконец, формы сослагательного наклонения в главной части задают ирреальное условно-уступительное значение:

(9)

\begin{tabular}{|c|c|c|c|c|c|c|}
\hline $\begin{array}{l}\text {...Эсэг-ые-ции } \\
\text { отец-асc-poss2sg }\end{array}$ & \multicolumn{2}{|c|}{$\begin{array}{l}\text { Удэшэ-жэ } \\
\text { провожать-cvb }\end{array}$} & \multicolumn{2}{|c|}{$\begin{array}{l}\text { ошо-хо } \\
\text { идти-рc.fut }\end{array}$} & \multicolumn{2}{|c|}{$\begin{array}{l}\text { hанаа-тай-шье } \\
\text { желание-prop-pcl }\end{array}$} \\
\hline $\begin{array}{l}\text { hаа-мни, } \\
\text { pcl-poss1sg }\end{array}$ & \multicolumn{2}{|l|}{$\begin{array}{l}\text { бархир-даг, } \\
\text { плакать-рс.hab }\end{array}$} & $\begin{array}{l}\text { муу ёротой } \\
\text { вредный }\end{array}$ & \multicolumn{3}{|c|}{ 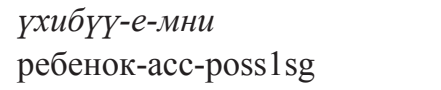 } \\
\hline ha. & \multirow{2}{*}{ hахи-жа } & \multicolumn{2}{|l|}{ үлэ-хэ } & \multicolumn{3}{|c|}{ бай-гаа-б } \\
\hline пр & & остават & гься-рс.fut & aux & prs-pcl & $\mathrm{pcl}$ \\
\hline
\end{tabular}

'Даже если бы я хотела сопровождать твоего отца, кто остался бы присматривать за моим плаксивым, вредным ребенком?’ [ЭКБЯ. Тулаев В. Алтан хараасгай. 1979].

Полисемантическая скрепа аaд, традиционно называемая противительным союзом, способна, как описано выше, передавать также причинные и условные отношения. В определенном контексте она выражает уступительно-противительное значение 'хотя.., но': в обеих ПЕ описываются противоположные события, в главной части происходит событие вопреки ожиданиям. В этой конструкции обязательно наличие одного под- лежащего (моносубъектность), ср. сочетание хотя с союзом но в уступительных структурах русского языка [Николаева, Фужерон 1999: 23]. Условно-уступительное здесь невозможно ни в реальном, ни, тем более, в ирреальном варианте; действие зависимой части всегда фактивно. Поэтому временная форма главного глагола не имеет значения, уступительно-противительное прочтение сохраняется в любом случае. Сравним:

\begin{tabular}{|c|c|c|c|c|}
\hline $\begin{array}{l}\text { ЗҮYн } \\
\text { левый }\end{array}$ & $\begin{array}{l}\text { дала-нь } \\
\text { лопатка-poss3 }\end{array}$ & $\begin{array}{l}\text { аймшагтай } \\
\text { страшный }\end{array}$ & $\begin{array}{l}\text { ехээр } \\
\text { много }\end{array}$ & $\begin{array}{l}\text { холо-hон } \\
\text { натереть-pc.pst }\end{array}$ \\
\hline $\begin{array}{l}\text { aad, } \\
\mathrm{pcl}\end{array}$ & зеть-pc.prs[3sg & & & \\
\hline
\end{tabular}

'Хотя его левая лопатка чрезвычайно сильно была натерта, но зажила' [ЭКБЯ. Д. Эрдынеев. Хүлэг инсагаална. 1974].

\begin{tabular}{|c|c|c|c|c|}
\hline $\begin{array}{l}\text { Уншалга-яа } \\
\text { молебен-refl }\end{array}$ & $\begin{array}{l}\text { Үни } \\
\text { давно }\end{array}$ & $\begin{array}{l}\text { дҮУргэ-һэн } \\
\text { закончить-pc.pst }\end{array}$ & $\begin{array}{l}\text { aad, } \\
\mathrm{pcl}\end{array}$ & $\begin{array}{l}\text { манжал-хаяа } \\
\text { пить чай-pc.fut:acc }\end{array}$ \\
\hline $\begin{array}{l}\text { яара-на-гүй } \\
\text { торопиться-р }\end{array}$ & 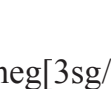 & & & \\
\hline
\end{tabular}

Фактивность подчеркивается еще и тем, что появление форм сослагательного наклонения у главного глагола с зависимой частью этой структуры невозможно:

*Доржо мүнгөө абаа-шье-гүй аад, үхибүудтээ заал һаa бэлэг асар-ха һэн -
'Даже если бы Доржо не получил денег, он бы обязательно купил детям подарок'.

По мнению информантов, такая зависимая часть обязательно получает следующее продолжение:

\begin{tabular}{|c|c|c|c|}
\hline $\begin{array}{l}\text { Доржо } \\
\text { Доржо }\end{array}$ & $\begin{array}{l}\text { мүнг-өө } \\
\text { деньги-reft }\end{array}$ & $\begin{array}{l}\text { аб-аa-иье--гүй } \\
\text { брать-pc.prs-pcl-neg }\end{array}$ & $\begin{array}{l}\text { aad, } \\
\mathrm{pcl}\end{array}$ \\
\hline$\gamma-\partial-m-\ni \ni$ & бэлэг & acap-aa & \\
\hline енок-pl-dat-refl & подарок & приносить-рс.prs & \\
\hline
\end{tabular}

Также в отличие от других уступительных конструкций, в конструкции с аaд временной интервал между событиями обычно растянут (10), поэтому следующие примеры выглядят несколько странными: 


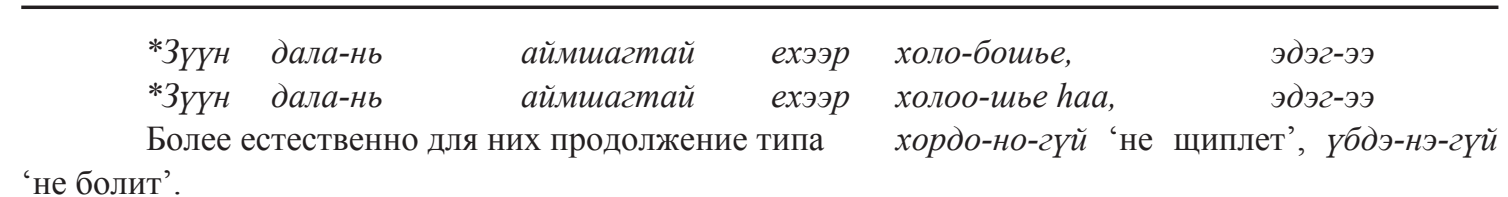

Уступительно-противительные конструкции со скрепами на базе служебных глаголов, образованные от дицендиального глагола гэ-, соединяют либо части собственно сложных предложений (бифинитные конструкции), либо текстовые отрезки. В бифинитных конструкциях чаще всего

$\begin{array}{ll}\text { Энэ } \quad \text { англи } & \text { хэлэн-иинь } \\ \text { этот } \quad \text { английский } & \text { язык-poss3 } \\ \text { эбдэ-жээрхи-хээр } & \text { гэ-бэшье, } \\ \text { ломать-intens-pc.pot } & \text { pcl } \\ \text { дабта-н } & \text { дарья-на-д } \\ \text { повторять-сvb } & \text { галдеть-prs-pl }\end{array}$

'Хотя (можно сказать, что) на этом их английском (языке) можно язык сломать, все ее ученики галдят, повторяя за учителем’ [ЭКБЯ. Ц.-Ж. Жимбиев. Урасхал. 1973].

В этом случае, как представляется, основа глагола говорения гэ- привносит дополнительный модусный компонент - подчеркивание индивидуальной интерпретации событий со стороны самого говорящего, автора текста.

Однако гораздо чаще (в соотношении 1:16) скрепа гэбэшье употребляется в начале линейно второй части, либо следующего отрезка текста, выражая значение 'тем не менее, несмотря на' (по мнению М. В. Ляпон, в русском языке уступительное зна- встречается скрепа гэбэшье, имеющая два типа дистрибуции. Во-первых, она может располагаться в конце линейно первой части: здесь еще можно соотнести ее с уступительной деепричастной формой от глагола гэ- 'говорить, сказать':

\begin{tabular}{lll} 
хүн-эй & \multicolumn{1}{c}{ хэлэ } & \multicolumn{1}{c}{ ама-яа } \\
человек-gen $\quad$ язык & рот-refl \\
бүхь & hурагша-д-ьнь & багша-яа \\
все & ученик-pl-poss3 & учитель-refl
\end{tabular}

чение в чистом виде выражается союзом несмотря на то, что и его семантическими эквивалентами [Ляпон 1986: 139]). Такое употребление сходно с употреблением скрепы тиигэбэиье от местоименного глагола тиигэ-, т. е. можно предполагать лексикализацию данной формы в качестве уступительно-противительного связующего средства. Противительного - поскольку перенос скрепы в линейно вторую часть связан также с переносом логического выделения:
Тэнгэри-ин зүҮн хаяа сай-жа
небо-gen восточный край
холо
хара-х-ьын
белеть-cvb
эхилэ-нхэй.
Гэ-бэшье
аргагуй начинать-pc.res
conj
далеко
видеть-pc.fut-gen
невозможно
үшөө-л
бүрэнхызандаа
темный pstp
'Восточный край неба уже начал светать. Но, тем не менее, невозможно видеть далеко, все еще темно’ [ЭКБЯ. Г.-Д. Дамбаев. Эжын хоер. 1982].

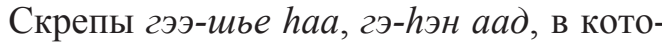
рых прослеживается связь с глаголом речи гэ-, встречаются гораздо реже, форма гэ-һэн aаd с причастием будущего времени грамматикализуется в качестве противительного союзного слова.

Таким образом, в первом типе конструкций скрепа гэбэщье сигнализирует о присутствии субъективной интерпретации событий, во втором - представляет собой грамматикализовавшееся союзное средство выражения уступительно-противительных отношений уже на уровне текста.

Заключение. Из четырех квазисинонимических конструкций уступки деепричастная конструкция на -бАшье ограничена книжным стилем употребления и преимущественно выражает причинно-у- 
ступительные отношения, а также подлежащее в ней выражает только 3-е лицо. Принципиально моносубъектная конструкция с аад акцентирована на выражении уступительно-противительных отношений с расширенным временным интервалом между событиями. Скрепа гэбэшье в линейно первой части конструкции, передавая уступительное значение, сохраняет модусный компонент значения 'хотя можно

\section{Сокращения}

МСФ - моносубъектная фраза

РСФ — разносубъектная фраза

ГПЕ - главная предикативная единица

ЗПЕ - зависимая предикативная единица

\section{Глоссы}

$\mathrm{V}$ - глагол, глагольная основа

$\mathrm{N}$ - имя

A - прилагательное

$\mathrm{L}$ - лексема

NOM - неопределенный падеж

GEN — родительный падеж

ACC - винительный падеж

DAT - дательно-местный падеж

$\mathrm{ABL}$ - исходный падеж

INS - орудный падеж

COM - совместный падеж

SG - единственное число

PL - множественное число

PASS - страдательный залог, пассив

INTENS - интенсивное действие

SOC - совместное действие

PST - прошедшее время

PRS - настоящее время

FUT - будущее время

PCL - частица

PSTP - послелог

REFL - притяжание

POSS - личное притяжание

CVB - деепричастие

PC - причастие

\section{Источники}

ЭКБЯ - Электронный корпус бурятского языка [электронный ресурс] // URL: http://webcorpora.net/BuryatCorpus/search/?interface language=ru (дата обращения: 20.06.201624.09.2016).

\section{Sources}

[Online Corpus of the Buryat Language ('The Buryat Corpus')]. An Internet resource: http:// сказать, что...'. К продуктивному ядру относится конструкция со скрепой - $A A$-шье haa, способная выражать как причинно-уступительные, так и условно-уступительные реальные и ирреальные значения (в зависимости от формы глагола-сказуемого в главной части). Таким образом, дифференциация квазисинонимических конструкций способствует уточнению и нормированию отношений между ними.

web-corpora.net/BuryatCorpus/search/index. php?interface_language=ru (accessed: June 20, 2016 - September 24, 2019). (In Bur.)

\section{Литература}

Амоголонов 1958 - Амоголонов Д. Д. Современный бурятский язык. Улан-Удэ: Бурятск. кн. изд-во, 1958. 336 с.

Апресян 2006 - Апресян В. Ю. Уступительность как системообразующий смысл // Вопросы языкознания. 2006. № 2. С. 85-111.

Арутюнова 1988 - Арутюнова Н. Д. Типы языковых значений. Оценка. Событие. Факт. М.: Наука, 1988. 341 с.

Бертагаев 1968 - Бертагаев T. А. Бурятский язык // Языки народов СССР. Т. 5. Л.: Наука, ЛО, 1968. С. 13-33.

Булыгина, Шмелев 1997 - Бульгина T. В., Шмелев А. Д. Языковая концептуализация мира (на материале русской грамматики). М.: Языки русской культуры, 1997. 576 с.

Валиева 2014 - Валиева Л. Г. Кондициональные и уступительные отношения в тюркских языках // Вестник Воронежского государственного университета. Серия: Лингвистика и межкультурная коммуникация. 2014. № 2. С. 100-104.

Ляпон 1986 - Ляпон М. В. Смысловая структура сложного предложения и текст. К типологии внутритекстовых отношений. М.: Наука, 1986. $200 \mathrm{c}$

Николаева, Фужерон 1999 - Николаева T. М., Фужерон И. Некоторые наблюдения над семантикой и статусом сложных предложений с уступительными союзами // Вопросы языкознания. 1999. № 1. С. 17-37.

Паршин 1988 - Паршин П. Б. Уступка и антиуступка в деонтическом диалоге (функционирование лексемы хоть) // Референция и проблемы текстообразования. Логический анализ языка. М.: Наука, 1988. С. 146-168. 
Поппе 1938 - Попnе Н. Н. Грамматика бурят-монгольского языка. М., Л.: Изд-во АН СССР, 1938. 268 c.

Русская грамматика 1980 - Русская грамматика. М.: Наука, 1980. 709 с.

Теремова 1986 - Теремова Р. М. Семантика уступительности и ее выражение в современном русском языке. Л.: Ленингр. пединститут им. А. И. Герцена. 1986.75 с.

Типология уступительных... 2004 - Типология уступительных конструкций. СПб.: Наука, 2004. 625 c.

Урысон 2002 - Урысон Е. В. Союз хотя сквозь призму семантических примитивов // Вопросы языкознания. 2002. № 6. С. 35-54.

Храковский 1998 - Храковский В. С. Теоретический анализ условных конструкций // Типология условных конструкций. СПб.: Наука, 1998. С. 7-96.

Шувалова 1990 - Шувалова C. А. Смысловые отношения в сложном предложении и способы их выражения. М.: Изд-во МГУ, 1990. 159 c.

König 1991 - König Ekkehard. Concessive relations as the dual of causal relations // Semantic universals and universal semantics / D. Zafferer (ed.), Dordrecht: Foris, 1991. Pp. 190-209.

Wierzbicka 1987 - Wierzbicka A. English speech act verbs: a semantic dictionary. Sydney: Academic press, 1987. 397 p.

\section{References}

[Russian Grammar]. Moscow: Nauka, 1980. 709 p. (In Russ.)

[Typology of Concessive Constructions]. St. Petersburg: Nauka, 2004. 625 p. (In Russ.)

Amogolonov D. D. [The Modern Buryat language]. Ulan-Ude': Buryat Book Publ., 1958. 336 p. (In Russ.)

Apresyan V. Yu. Concessiveness as a meaning to create the system. Voprosy Jazykoznanija. 2006. No. 2. Pp. 85-111. (In Russ.)

Arutyunova N. D. [Types of Linguistic Meanings: Assessment, Event, Fact]. Moscow: Nauka, 1988. 341 p. (In Russ.)

Bertagaev T. A. The Buryat language. In: [Languages of the Soviet Peoples]. Vol. 5. Leningrad. 1968. Pp. 13-33. (In Russ.)
Bulygina T. V., Shmelev A. D. [Language Conceptualization of the World: a Case Study of Russian Grammar]. Moscow: Yazyki Russkoy Kul'tury, 1997. 576 p. (In Russ.)

Khrakovsky V. S. Theoretical analysis of conditional structures. In: [Typology of Conditional Constructions]. St. Petersburg: Nauka, 1998. Pp. 7-96. (In Russ.)

König Ekkehard. Concessive relations as the dual of causal relations. In: Semantic Universals and Universal Semantics. D. Zafferer (ed.). Dordrecht: Foris, 1991. Pp. 190-209. (In Eng.)

Lyapon M. V. [The Semantic Structure of Complex Sentences and Text: Typology of Intertextual Relations Revisited]. Moscow: Nauka, 1986. 200 p. (In Russ.)

Nikolaeva T. M., Fuzheron I. Some observations on the semantics and status of complex sentences with concessive conjunctions. Voprosy Jazykoznanija. 1999. No 1. Pp. 17-37. (In Russ.)

Parshin P. B. Concession and anti-concession in the deontic dialogue (functioning of the lexeme xomb 'though'). In: [Referencing and Text Production Issues. Logical Analysis of Language]. Moscow: Nauka, 1988. Pp. 146168. (In Russ.)

Poppe N. N. [Buryat-Mongolian Grammar]. Moscow, Leningrad: USSR Acad. of Sc., 1938. 268 p. (In Russ.)

Shuvalova S. A. [Semantic Relations in Complex Sentences and Their Expression] Moscow: Moscow State Univ., 1990. 159 p. (In Russ.)

Teremova R. M. [Semantics of Concessiveness and Its Expression in Modern Russian]. Leningrad: Herzen Leningrad Pedagogical Inst., 1986. 75 p. (In Russ.)

Uryson E. V. The conjunction xomb 'though' through the prism of semantic primitives. Voprosy Jazykoznanija. 2002. No. 6. Pp. 3554. (In Russ.)

Valieva L. G. Conditional and concessive relations in Turkic languages. Proceedings of Voronezh State University. Ser. 'Linguistics and CrossCultural Communication'. 2014. No. 2. Pp. 100-104. (In Russ.)

Wierzbicka A. English Speech Act Verbs: a Semantic Dictionary. Sydney: Academic Press, 1987. 397 p. (In Eng.) 